\title{
RESEARCH OF POLYMERIC EXTRUDATE WITH SEGMENT-WALL CONSTRUCTION
}

\author{
Sebastian Białasz' ${ }^{1}$ Isidoro Martinez ${ }^{2}$
}

1 Lublin University of Technology, Mechanical Engineering Faculty, Department of Technology and Polymer Processing, 36 Nadbystrzycka St., 20-618 Lublin, Poland, e-mail: sebastian.bialasz@pollub.edu.pl

2 Universidad Politecnica de Cartagena, Department of Materials and Manufacturing Engineering, 30202 Cartagena, Spain, e-mail: isidoro.martinez@upct.es

Received: 2018.07.15

Accepted: 2018.08.05

Published: 2018.09.01

\begin{abstract}
This paper presents the characteristics of the production of extrudate with axial-symmetrical construction, having a segmented construction wall. Examples of machine tools and devices for manufacturing products with segments and the construction characteristics of a single segment are presented. Methods of shaping the segment wall in forming sockets, characteristics and type of movement made by shaping elements in the process of extrusion in the process line are described. Exemplary results of experimental investigations of the displacement of geometric elements of a single segment and the influence of wall thickness on segment deformation at a given force and speed of deformation under laboratory conditions are presented.
\end{abstract}

Keywords: extrusion, segment-wall, axial-symmetrical, pipe.

\section{INTRODUCTION}

Axial-symmetrical products produced in the extrusion process line in a form of ducts, tubes and profiles are successfully used in various technical solutions. They are made of many different materials (PE, PP and PVC or PB), which are selected for the required functions and specific functional characteristics $[4,9,10,13]$. There are known methods of extruding plastics covering various materials and technologies leading to obtaining products with various characteristics and properties $[3,4,14,15]$. Due to the well-known process of their production in the process line, it is possible to easily modify the shape of the product $[1,7,12]$. This is done most often by changing the tool or by performing additional technological measures, such as shaping the slide ribs, shaping the segmented wall or by spraying an additional layer of sliding agent on the desired surface. This leads to axial-symmetrical structures with uniform or geometrically homogeneous inner or outer surfaces with an additional elevated tribological properties [11]. The geometrically inhomogeneous surface usually has characteristic macrofolds or macroscopies, which may be continuous or discontinuous, run longitudinally, transversally, helically or alternately torsionally. Geometric elements of longitudinal macropervation (grooves, ribs) of appropriate shapes and dimensions can be performed in the extrusion process using special cores or forming sleeves. However, the desired transverse macro transitions can be made in devices with circulating forming sockets. An additional technological process of shaping in the sockets is most often carried out with the use of vacuum extrusion of the extrudate wall, which obtains the final shape during cooling [12]. This technique produces embossing, single-layer or double-layer, and synchronizing the boring process with the movement of forming slots, allows for accurate mapping of the required macro conversions [8]. 

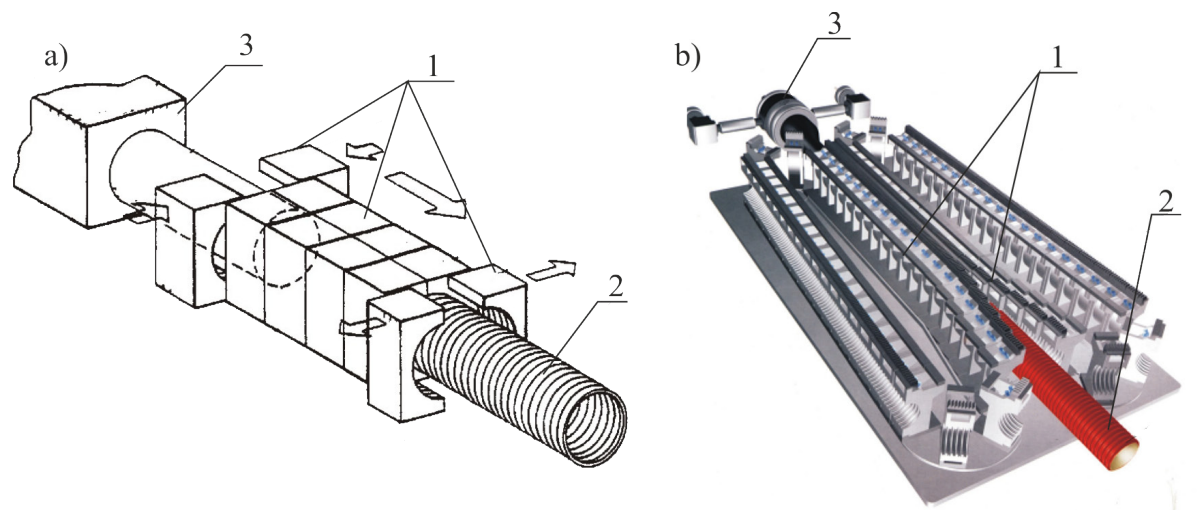

Fig. 1. The scheme of shaping the extrudate wall by means of forming sockets: a) several in a sliding system, b) a dozen or so in the circulation system: 1 - shaping segments, 2 - extrudate, 3 - extrusion head $[18,20]$

\section{SHAPING PRODUCTS WITH SEGMENTED WALL CONSTRUCTION}

To produce extruded structural walls with characteristic segments, tools are used that form the plasticized extrudate in special slots coupled together in a suitable kinematic system (Fig. 1a). Underpressure or also compressed air, supplied by appropriate conduits, extends the extrudate and then deformation of the wall in accordance with the shape of the cavity [20].

The extrudates with a two-layer wall with an inner cylindrical layer, and the outer sectional ones are produced in turn using special heads. A characteristic feature of this process is the use of two plasticizing systems and only one tool. The desired product is obtained by connecting together co-extruded two extrudates having a

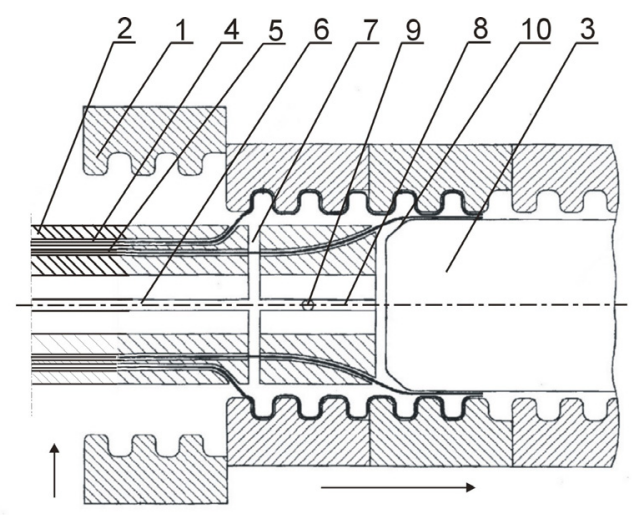

Fig. 2. Diagram of forming a two-layer extrudate with segmental construction: 1 - forming sockets, 2 extrusion head, 3 - conical core part, 4, 5 - plasticized material, 6, 7, 8 - compressed air supply ducts, 9 valve, 10- core ending [16] smaller diameter on the inner wall and a larger one on the outer wall, when two outer forming shaping nests close on its circumference. They give the extrusion the desired shape and move with it for a specific period of time. After cooling the product section, the mold cavities move to the initial position (Fig. 1b).

In case of a two-layer extrudate, the plasticized material of the first layer flows over the compressed air supply duct (Fig. 2), which enables the mold cavities to be precisely filled. The stream of the second material is directed right towards the conical core and forms the inner layer of the product. The appropriately shaped conical part of the core and the intensity of the compressed air stream (regulated by the valve) allow for precise control of the wall thickness of the extruded product. The shape of the conical core surface is sinusoidal with gentle ridges in which the material contacts

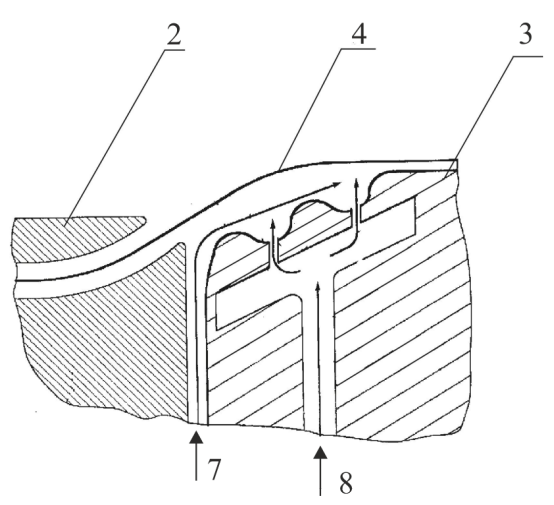

Fig. 3. The principle of shaping the inner extrudate layer: 2 - extrusion head, 3 - conical core part, 4 plasticized material, 7, 8 - compressed air supplying ducts [16] 


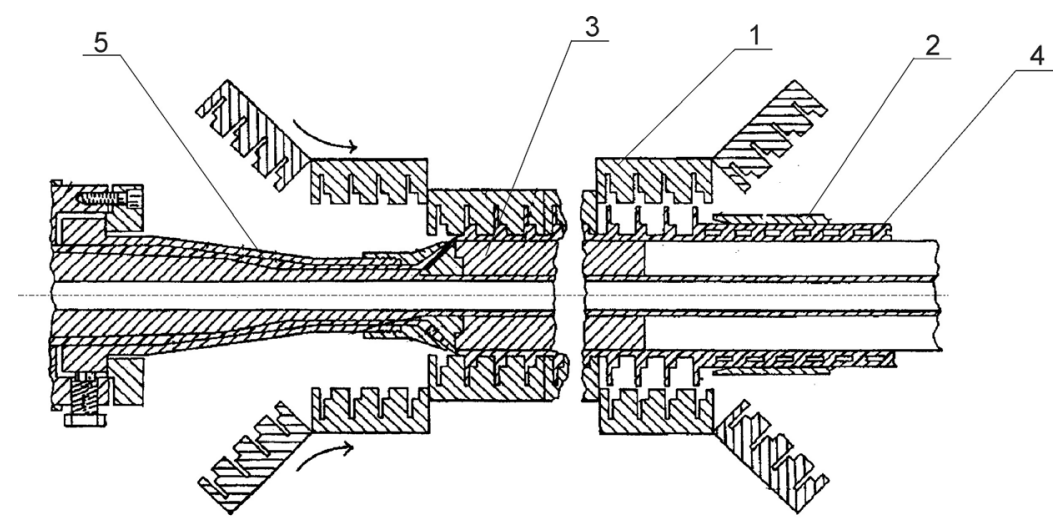

Fig. 4. Production of extrudate with air chambers, 1 - forming sockets, 2 - pressing bushing, 3 - internal calibrator, 4 - prepared pipe, 5 - extrusion head [17]

a)

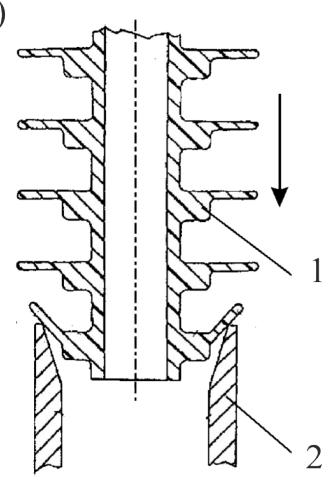

b)

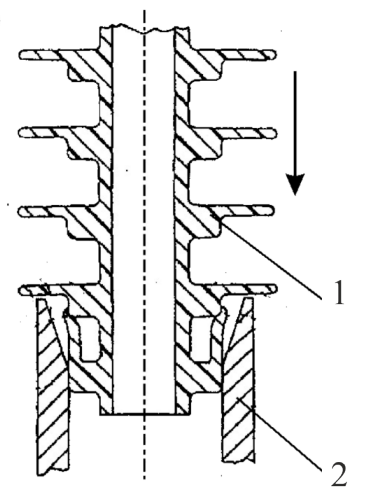

c)

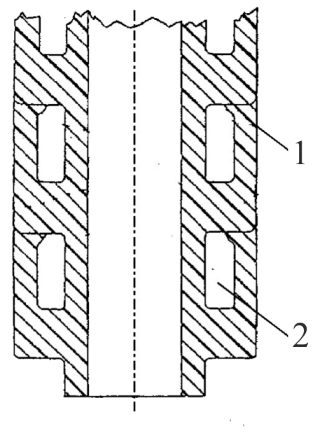

Fig. 5. Diagram of shaping closed chambers on the outer surface of the extrudate: 1 - rib, 2 - bending sleeve for ribs, 3 - created air chamber [17]

the core. The compressed air flows in the appropriate channels and is directed perpendicular to the surface of the flowing material. This results in the "lifting" of the flowing stream (Fig. 3) of the plastic and forming between it and the core of the air cushion, which prevents premature adhesion of the material to the core surface [16].

Another solution for a segmented wall construction product is extruded with closed air chambers. (Fig. 4). In this case, the cavities form the wall in two stages. In the first stage, high ribs are formed perpendicular to the axis of the extrudate. However, in the second stage, the entire extrudate along with the ribs is pulled through a special sleeve (Fig. 5), which, depending on the size of the ribs and the state of their plasticity, bends them to the surface of the product [17]. By bending and pressing, the individual tops of the ribs adhere to the wall creating, after cooling, closed air chambers on the outer surface of the extrudate.

\section{MACHINES, TOOLS AND DEVICES}

Axial-symmetrical products are manufactured on specially designed technological lines (Fig. 6), where the basic machine is a single screw extruder. Its task is to provide the tool with a homogenized material at a given flow rate, pressure and temperature. The custom of polyethylene and polypropyl-

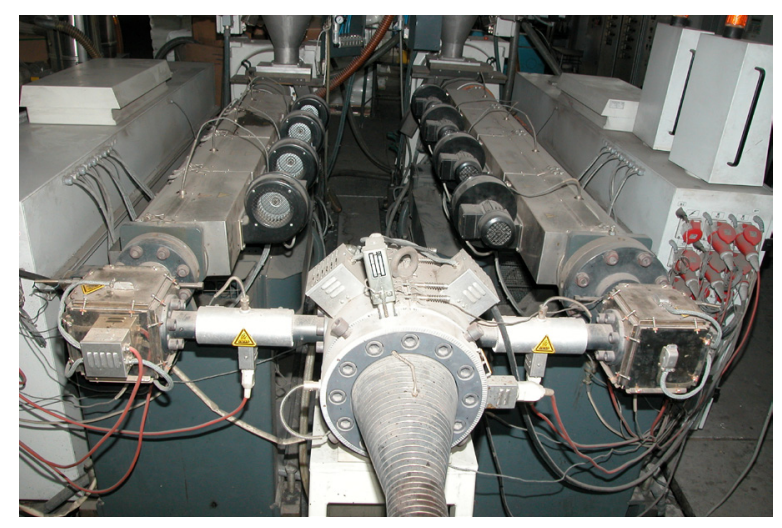

Fig. 6. The appearance of two plasticizing systems and a head for producing a two-layer extrudate 


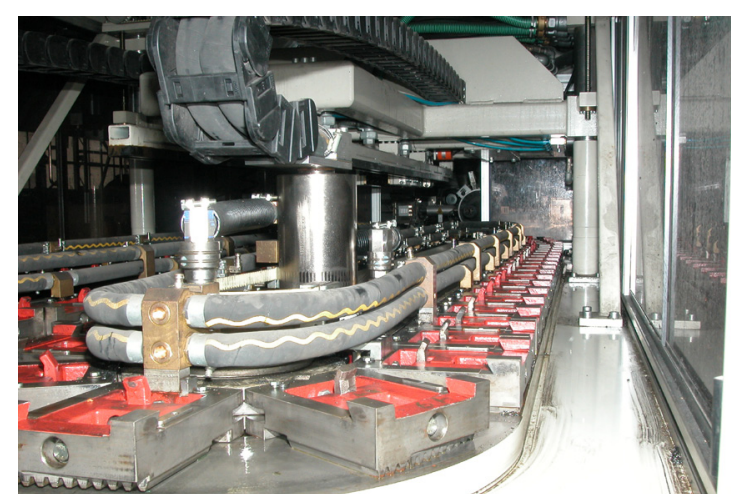

Fig. 7. The appearance of the vacuum system and the control of the movement of the cavities

ene extruders is customary, single-screw extruders, whereas poly (vinyl chloride) extrusions are made on twin screw extruders [7, 12].

The shape of the outer surface of the extrudate can be transmitted in several mold cavities or, which is more often used, in a larger number of them. In this case, the sockets are connected to each other in a single system with a circulatory crawler exhaust (Figure 7) moving along with the extruded. This requires precise synchronization of the time of turning on the forming vacuum with the movement of the sockets and the feed of the extrudate [20], as well as the cooling time in the sockets after the wall has been formed (Fig. 8 and Fig. 9).

\section{THE CONSTRUCTION OF THE SEGMENT WALL}

The products made of polymer material may differ not only in the appearance, purpose and method of manufacture but also in different prop-
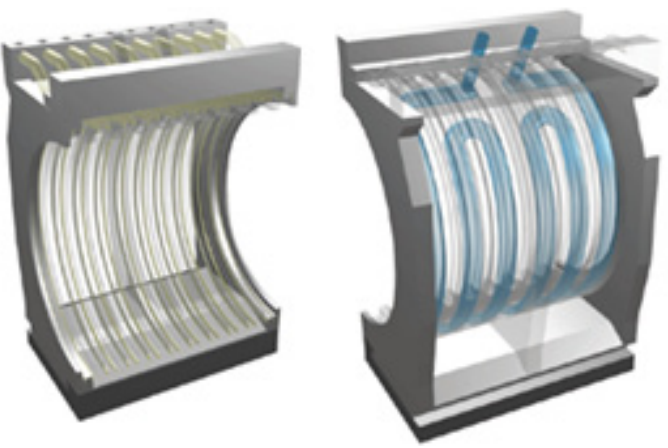

Fig. 8. Appearance of a single forming nest with a system of vacuum channels and a cooling channel system [20]

erties influenced mainly by the wall construction. In the case of axially symmetrical products, depending on the dimensions of the segments, i.e. their height, width, spacing between them, and the wall thickness, the extrudate may exhibit increased circumferential stiffness, i.e. resistance to compression, bending and stretching or increased flexibility, with slightly reduced mechanical properties. By analyzing the structure of individual segments, it can be shown that their thickness in individual areas can vary. The elements which have the greatest thickness are those which are first in contact with the forming seat, which are the side and top walls of the segment. The smaller thickness, have the elements of the wall that are thinning due to stretching. In addition, in the case of two-layer pomace, excessive clusters of material may be formed at the bonding points of the layers. This increases the cooling time in this area, which affects the flexibility of the extrudate. As a result of external forces, uneven stress dis-

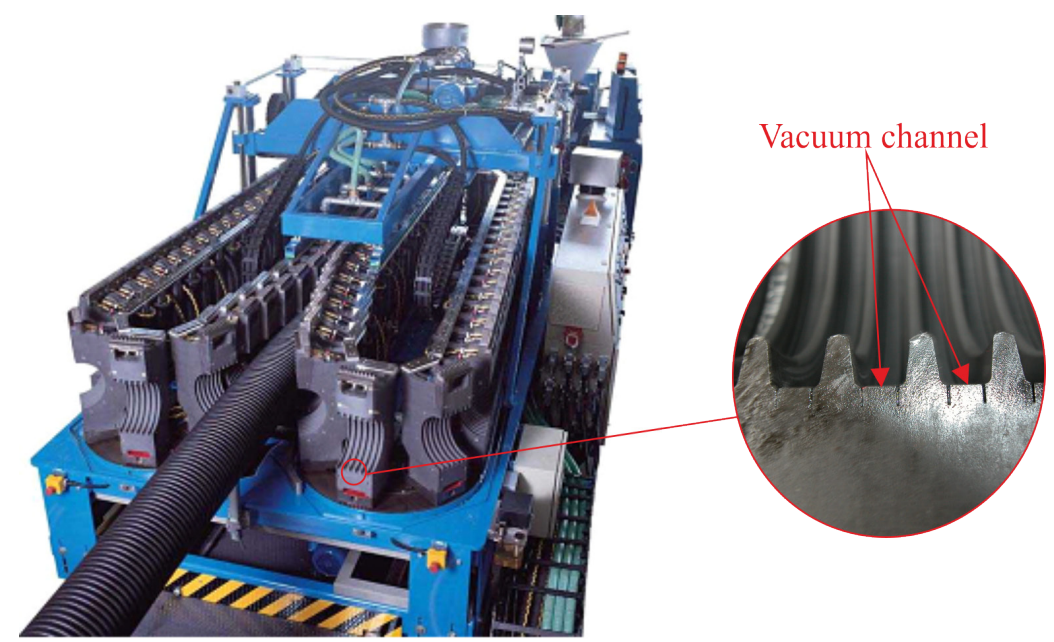

Fig. 9. Appearance of circular forming seats in tracked system and appearance of the enlarged fragment of the seat with a vacuum channel [20] 


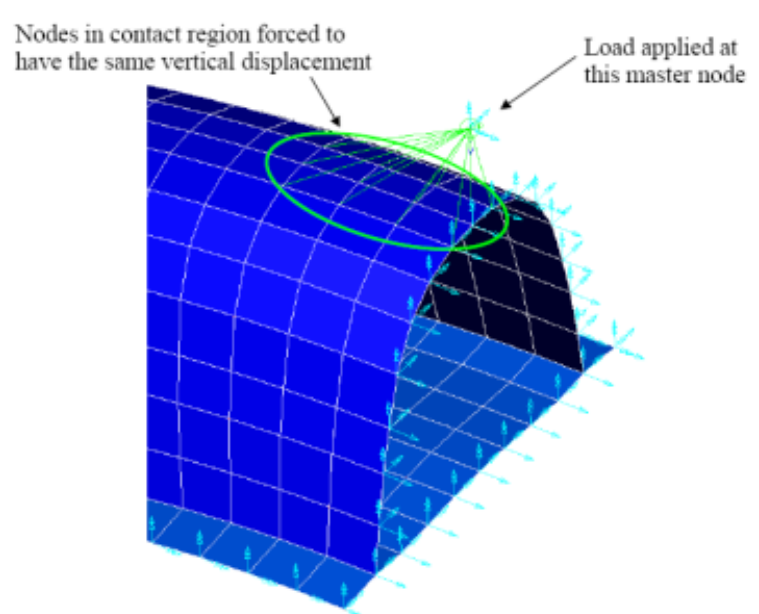

Fig. 10. The appearance of the FEA analysis determining the state of stresses and displacements of a single extrudate segment [19]

tribution may also occur in these areas. Thus, an even distribution of wall thickness in the entire segment plays a significant role in obtaining satisfactory mechanical properties of the product.

There is a large number of standards and requirements describing testing of entire product structures [1] with segment wall, such as tests for resistance to internal pressure, peripheral stiffness, impact resistance at reduced temperature, and others. In recent years, due to the development of FEM modeling methods (Fig. 10), some of the research can be carried out in virtual space $[2,5,19]$. However, the input data for the calculations is made by conducting tests on selected extrudate elements, in particular in the area of a single segment. Such tests allow for accurate identification of the correctness of the constructed structure, determining the values of indicators describing the resistance of the segment to concentrated forces acting on the outer wall of the

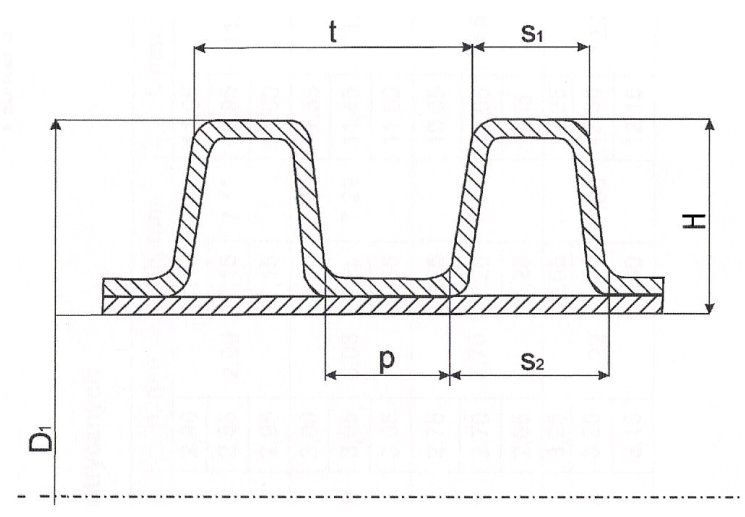

Fig. 11. A fragment of a longitudinal section of a pipe with a structural structure with measurement locations defining geometrical dimensions of the outer layer of the tested pipes, where: $\mathrm{D}_{1}$ - diameter of pipe; t- graduation; $\mathrm{S}_{1}, \mathrm{~S}_{2}$ - segment width; $\mathrm{H}$ - segment height, p- width between segments

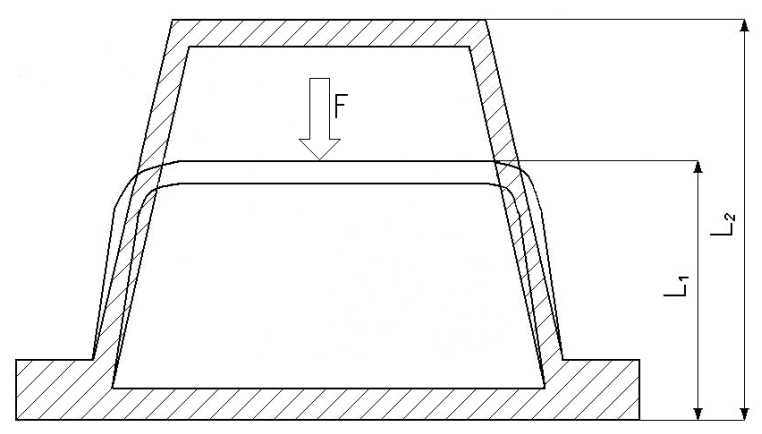

Fig. 12. Diagram showing the displacement of the segment edges under the influence of the concentrated external force, where: $\mathrm{L}_{1}$ - height after press; $\mathrm{L}_{2}-$ height before press

extrudate in a specific area, taking into account the conditions similar to its operation.

For the numerical analysis, the results of experimental research on products in a form of axial-symmetric segment slices with a segmen-

Table 1. Features of geometric elements of the extrudate with a segmental wall

\begin{tabular}{|c|c|c|c|c|}
\hline \multicolumn{2}{|c|}{ Sample designation } & $\mathrm{w}_{1}$ & $\mathbf{W}_{2}$ & $W_{3}$ (with wall defects) \\
\hline \multicolumn{5}{|c|}{ The appearance of the sample } \\
\hline \multicolumn{2}{|c|}{ Diameter $\mathrm{D}_{1}[\mathrm{~mm}]$} & 110 & 110 & 110 \\
\hline \multirow{5}{*}{$\begin{array}{l}\text { Dimensions } \\
\text { of segments } \\
{[\mathrm{mm}]}\end{array}$} & width between segments, $p$ & 3,65 & 2,90 & 3,00 \\
\hline & segment width, $\mathrm{S}_{1}$ & 6,25 & 5,95 & 6,00 \\
\hline & segment width, $\mathrm{S}_{2}$ & 7,50 & 7,90 & 8,25 \\
\hline & segment height, $\mathrm{H}$ & 6,50 & 7,05 & 6,55 \\
\hline & graduation, $\mathrm{t}$ & 12,00 & 12,70 & 12,40 \\
\hline
\end{tabular}



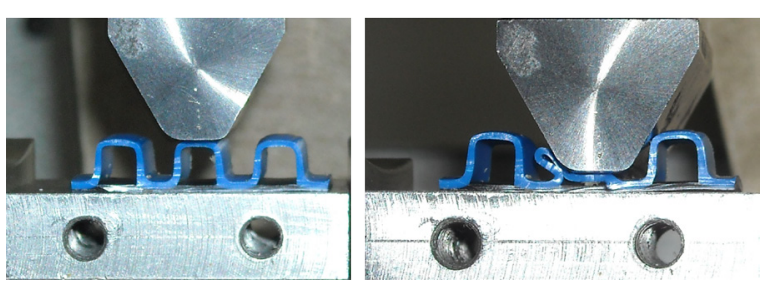

Fig. 13. Appearance of the method of testing the wall segment deformation during a hydraulic press

tal wall are needed. Therefore, as an example, the results were presented for the shape of geometrical elements (Fig. 11) of segments and their resistance to external forces (Fig. 12). Segments of extrudate were taken from ducts made of high-density polyethylene (PE-HD), having an outer diameter of $110 \mathrm{~mm}$. The values of the obtained results of metrological measurements are included in the Table 1.

Measurements of segment deformation at a given force acting on individual samples were carried out on the AS-102 type press, in the Labo- ratory of the Polymer Processes Department. An exemplary course of deformation of the sample is shown in Fig. 13. The tests of the mechanical strength of the extrudate were made at different lengths of the punch contact surface with the extrudate section being 4 to $30 \mathrm{~mm}$ (Fig. 14), with a constant loading speed of $\mathrm{V}=39 \mathrm{~mm} / \mathrm{s}$. During the tests, the maximum value of the force at which the largest deformation of the segment occurred was read. Wall displacement value was determined according to the diagram shown in (Fig. 11).

Mechanical strength tests of marcing segments were also performed at different loading speeds: $\mathrm{V}_{1}=0.104 \mathrm{~mm} / \mathrm{s}, \mathrm{V}_{2},=0.39 \mathrm{~mm} / \mathrm{s}, \mathrm{V}_{3}=1$ $\mathrm{mm} / \mathrm{s}, V_{4}=2 \mathrm{~mm} / \mathrm{s}$. In this case, the length of the marcing samples was $25 \mathrm{~mm}$, and the measurement results are shown in Figure 15.

\section{CONCLUSIONS}

Research on products with segmented wall construction allows to indicate areas affecting the

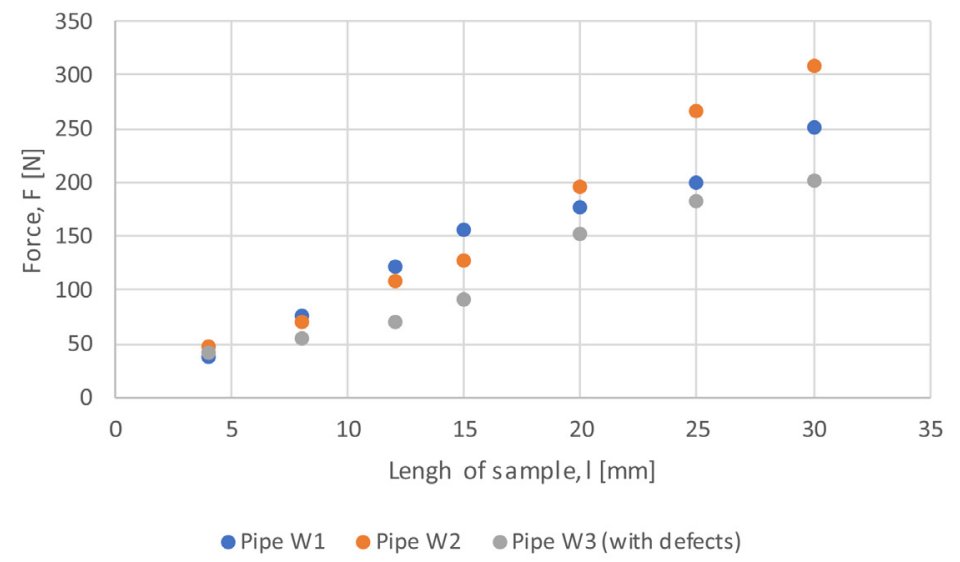

Fig. 14. The graph influences the length of the extrudate sample on the value of force at which the tested sample showed the greatest deformation value

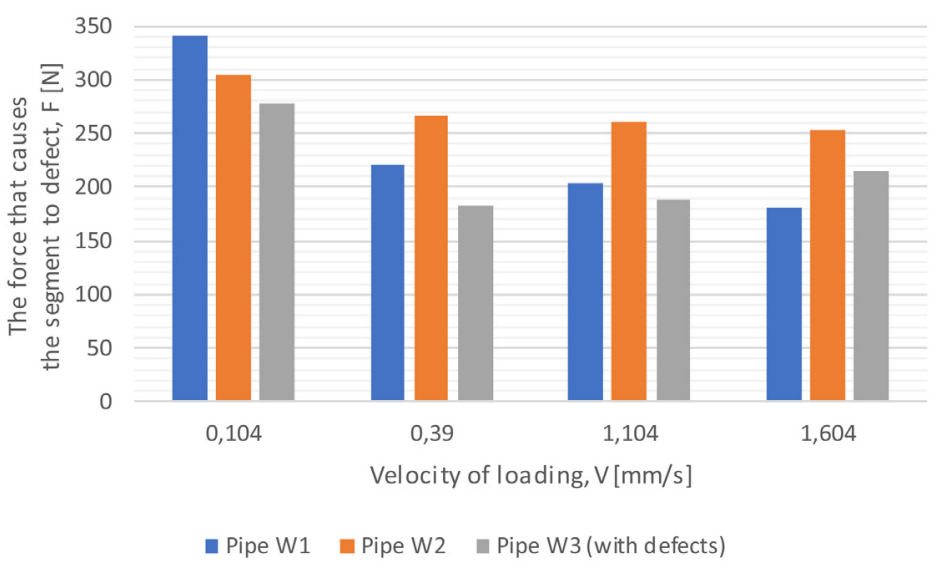

Fig. 15. Graph of changes in the speed of segment loading on the value of the force causing the deformation 
strength of the whole extrudate construction. On the basis of measurements of different etrudates in a form of samples with a diameter $\mathrm{D}_{1}=110$ $\mathrm{mm}$, having a segmented construction wall, they were noticed to show a significant variation of the dimensions of the characteristic elements while maintaining reproducible, in the adopted range of dimensions, individual segments (pitch, height and width of the segment ). All this has a significant impact on the mechanical properties of the obtained extrudate, primarily on the value of the stiffness and flexibility of the whole pipe. Analyzing the obtained results of measurements of the mechanical strength of the extruders subjected to compression, at a constant speed, it can be noticed that they indicate a proportional increase in the mechanical strength depending on the length of the test sample. The exception was a sample with a construction defect. This sample, marked with the symbol W3, with similar dimensions of the walls of the extrudate W2 showed much lower compressive strength. With a sample length of $1=$ $15 \mathrm{~mm}, \mathrm{~W} 1$ sample buckled at a strength of 155.5 $\mathrm{N}$, sample W2 at a strength of 127.5 , whereas a sample with a design defect exhibited strength only up to a force value of $90.5 \mathrm{~N}$.

The above conclusions are also confirmed by tests carried out on samples of constant length at varying loading rates. Based on the results of these tests, it can be noticed that the deformation of segments having structural defects has much lower mechanical strength. It results from uneven distribution of stresses depending on the wall thickness of the segment in its particular areas. Deviations from the assumed dimensions of particular geometric elements of this type of extrudate depend to a great extent on the course and conditions of the extrusion process in the extrusion process line as well as the appropriate synchronization of the extrusion rates with the circulating forming elements.

\section{REFERENCES}

1. Broniewski T, Kapko J., Płaczek W., Thomala J.: Metody badań i ocena właściwości tworzyw sztucznych. WNT, Warszawa, 2000.

2. Burgon, R. P., Folkman, S. L., Moser, A. P.: Parametric Study of Influence of Profile Geometry on Structural Performance of Buried Profile-Wall Pipe. Journal of the Transportation Research Bard. Vol. 2146. 2009.

3. Garbacz T.: Structure and properties of cellular thin-walled cable coatings. POLIMERY 2012, vol. 57, 11-12, p. 865-868.

4. Hyla I.: Tworzywa sztuczne, własności przetwórstwo - zastosowanie. Wydawnictwo Politechniki Śląskiej, Gliwice, 1999.

5. Klepka T., Jeziórska R., Szadkowska A.: Thin wall products made of modified high density polyethylene. Przemysł Chemiczny 2015, vol. 94, 8, p. 1352-1355.

6. Klepka T.: Parameters characterizing optotelecommunication cable and its innerduct interaction. Polimery 2001, vol. 46, issue 3, p. 192-201.

7. Łączyński B.: Metody przetwórstwa tworzyw sztucznych, WNT, Warszawa, 1973.

8. Moser, A. P. Buried Pipe Design, 2nd Edition. McGraw-Hill, New York, 2001, p. 146.

9. Pieluchowski, J. Puszyński A.: Technologia tworzyw sztucznych. WNT, 1998.

10. Sasimowski E., Sikora J., Królikowski B.: Effectiveness of polyethylene extrusion in a singlescrew grooved feed extruder. Polimery 2014, 6, vol. 59, p. 505-510.

11. Sikora R. Klepka T.: Przegląd konstrukcji rur optotelekomunikacyjnych z tworzyw. XII Konferencja: Projektowanie, stosowanie i eksploatacja elementów maszyn i urządzeń z tworzyw sztucznych, Częstochowa, 1996.

12. Sikora R.: Przetwórstwo tworzyw wielkocząsteczkowych, WE. Warszawa, 1993.

13. Szlezyngier W.: Technologia przetwórstwa polimerów. Politechnika Rzeszowska im. Ignacego Łukaszewicza, Rzeszów, 1990.

14. Tor-Świątek A., Garbacz T., Jachowicz T.: Quantitative Assessment of the Microscopic Structure of Extruded and Injected Low-Density Polyethylene Modified with Microspheres by Image Analysis. CELLULAR POLYMERS 2016, vol. 35,2 , p. 67-84.

15. Wróblewska-Krepsztul J., Rydzkowski T., Borowski G., Szczypiński M., Klepka T., Thakur V. K.: Recent progress in biodegradable polymers and nanocomposite-based packaging materials for sustainable environment. International Journal of Polymer Analysis and Characterization, vol. 23, 4, 2018, p. 383-395.

16. Patent US 6155815 : Pipe molding aparaturs with air assist of plastic onto cooling plug, 2000.

17. Patent US 6210617 : Aparaturs and method for adjusting a mandrel and kerenel while producing a plastic pipes, 2001.

18. http://www.plastmak.pl

19. http://www.ugs.com/products/nx/simulation/advanced/master_fem/index.shtml

20. http://www.unicor.com 